\title{
Community Participation in Community Correction Operation and Offender Re-Integration
}

\author{
Zondi C.Z. \\ University of Zululand
}

\begin{abstract}
This article is the result of the project conducted for community members in Mkhwanazi area. It focused on the challenges these members had in re integrating and supporting ex-offenders. The study analysed the information and knowledge that these members had on their role in the reintegration of exoffenders into the community.

The methods of data collection used were participant observation, group discussions and semistructured interviews. Primary data was obtained from members of the community under induna Mwandla (Port Durnford), Mthethwa (Port Durnford) and Mpanza (Matholonjeni)

It was found that community members needed to be educated on their role in the reintegration of ex offenders. This also needed to be an ongoing project. It was also established that the biggest issue affecting the project was essentially lack of communication between the members of the community and the Department of Correctional Services.

Community participation in community correction operations and offender reintegration proved to be effective, if there was shared knowledge between the people living in the area and the Department of Correctional Services.
\end{abstract}

\section{Introduction}

This study focused on the members of the community of inkosi Mkhwanazi. There is very little knowledge that the members of the community have with regards to ex-offenders who are brought back into their community. Members of the community assist in bringing the perpetrators of crime to justice but when they are released or brought back to community they are not informed of the reason of their release. They are also not ensured of their role in smooth reintegration and support to prevent exoffenders from falling back to crime.

The objective of this project was to encourage community participation in the sphere of correctional management, with the aim of having the community working together in partnership with several organisations.

The intended project outcome was to make the community aware of their role in the integration of ex-offenders back into community, welcome and support them. The project was significant in that it made a difference to the lives of people and contributed to problem-solving of crime phenomenon. It also created a better understanding of community involvement in preventing exoffenders from recidivism (falling back to crime)

This article begins with a literature review, which will provide background of the role of the community in re-integration of ex-offenders into the community and the government framework for community education, participation in community corrections operations and offender reintegration, legislation and policies.

The findings of the project are presented in two parts. The first part examines the theoretical tenets. The second part presents the discussion of the members of the community's life experiences and challenges they are faced with. These challenges are lack of information in terms of what happens after offenders have been incarcerated, why the offenders are brought back into the community before they finish serving sentences imposed upon them. Also the reason community members often saw vehicles from the Department of Correctional Services visiting some homesteads.

In this project it was found that community members need to be educated on their role in the reintegration of ex offenders. There is also lack of communication between the community members and the Department of Correctional Services. The project had a positive impact in that it built relationship between members of the community and the stakeholders who has a pivotal role to play in ensuring that the community work together in reintegration of offenders into the community.

Finally the article argues that the main challenges faced by these members of the community who were present in the workshop. For future projects, it would be more effective if members of Department of Correctional Services could be involved. 
On the first day when the project was introduced to tribal council they showed reluctance in approving the project. This was largely because of personal experience as victims of crime. They were under the impression that University was representing the Department of Correctional Services and thus wanted to condone criminal activities, and expect community members to forgive and accept criminals back into their communities. The issue of offenders having undergone behaviour correction in the correctional centres did not have meaning to community members.

During the second meeting with them when the overview of the project was explained, we managed to gain their trust and we were allowed to work within the community.

\section{Literature review}

The concept of community based corrections has existed for centuries. In the United States of America (USA) this approach can be traced from the halfway house in 1887 in New York City. The major contribution on this issue was provided by the Federal Prisoner's Rehabilitation Act of 1965 and the President's Crime Commission. In its 1967 report, it was stated that the new direction in corrections recognises that crime and delinquency are failures of the community as well as individual offender. The commission concluded that reintegration is likely to further much more readily by working with the offenders in the community than by incarcerations [13].

Lloyd, Ohlin, Miller, Robert and Coates cited by [13] opine that reintegration of the offender into the community is not a one-way process. They emphasised the need for the community to take active role in the process in treating the offender, a strategy which they call advocacy, which goes beyond reintegration.

Cullin in Van der Walt, Cronje and Smit (1982:30) defined crime as a social problem which when viewed criminological, is an act that has been shown to be actually harmful to society. It is an act that is in conflict with the stability of the society. It is, therefore, imperative that the community work together in bringing back stability and in producing well adjusted citizens.

It is very important that the community defines its role and strategically think of their plan of this process.

Correction of offenders is a societal responsibility. The White paper on Corrections, 2004, says that 'The rehabilitation of offenders and their reintegration into the society can only be truly successful meaningful if all stakeholders are allowed to participate in the process.' To this effect the participation of the community in strengthening and enhancing rehabilitation is crucial.

\subsection{Strategic thinking}

Strategic thinking refers to the seeing of the big picture and its operational or functional implications [10]. The purpose of strategic thinking is to discover imaginative ways of encouraging community participation. Strategic thinking also refers to a creative, divergent thought process. Strategic thinking and strategic planning are required in any thoughtful strategy making process and strategy formulation. The creative, groundbreaking plans for encouraging community participation in community corrections operations and offender re integration emerging from strategic thinking, still have to be operationalised through convergent and analytical thought (strategic planning). Analytical thought relates to the collection of relevant information and the analysis of data. Both strategic thinking and strategic planning are necessary and neither is adequate without the other [6].

\subsection{Strategic planning}

Khoza explained [6] strategic planning as a disciplined effort to produce fundamental decisions and actions that shape and guide what community leadership does: and why it does it, with a focus on the future of community corrections operations and offender re-integration.

Strategic planning also enables the community to adapt more quickly and more efficiently to changing circumstances. Furthermore, it provides the basis from which the community can lead positive actions to create its own future and to prevent negative actions.

Strategic planning has as its goal the monitoring of changes in external environment in order to formulate aims, objectives and plans so that the community can adjust to change. Besides, it indicates the direction in which the community moving is in the long run.

The following are the most important elements of strategic planning:

- It is ongoing, continuous learning process;

- It is a qualitative idea-driven process;

- It thoroughly analyses community leadership, its internal and external environment and its potential;

- It is based on thorough analysis of foreseen or predicted trends and scenarios of possible alternative future community safety plan;

- It is aimed at creating the community leadership's future; and

- When it is successful, it influences all areas of operations- thus becoming part of the community leadership's philosophy and culture [10]. 
It is therefore, appropriate to argue that strategic thinking and strategic planning are required in any thoughtful strategy-making process and strategy formulation. This creates groundbreaking plans for encouraging community participation in community corrections operations. Offender re-integration emerging from strategic thinking, still has to be operational through convergent and analytical thought (strategic planning). Both strategic thinking and strategic planning are necessary and neither is adequate without the other [5].

\subsection{Crime Prevention}

Crime prevention implies any activity by an individual or group, public or private that precludes the incidence of one or more criminal acts. Further, it involves an action to eliminate crime, violence and public fear of crime. Third objective can be achieved in three ways:

- By providing a strong deferent in the form of an affective criminal justice system,

- By changing the conditions which are though to cause them, and

- By altering the environment in which they occur [8].

The following are important levels of application:

2.3.1. Primary crime prevention. The physical and social characteristics in the community which provide opportunities for crime are concentrated upon. The purpose of primary crime prevention is to enter these circumstances in such a way that crime cannot be committed [6].

2.3.2. Secondary crime prevention. This involves the early identification and recognition of factors which contribute towards crime, the identification of potential criminals and the protection of other persons who are exposed to such.

2.3.3. Tertiary crime prevention. The most important characteristics here is to prevent recidivism in those who have succumbed to crime. The emphasis falls on the handling of the results of crime as well as on treatment further criminal behaviour ([9], White paper on corrections in South Africa 2004, South African Police Act 1995, [8], Criminal procedure Act 1977, Constitution of the Republic of South Africa 1996).

It should be kept in mind that social or community oriented crime prevention actions function more strongly on the primary and secondary levels because both levels are directed towards circumstances outside the individual and also imply activities of a preclusive nature that is measures which are employed before crime been committed. Tertiary prevention, on the other hand, is oriented more towards the individual and implies remedial or corrective action- that is, rehabilitation of the offender [6].

\subsection{Approaches to crime prevention}

Three approaches are distinguishable law enforcement, situational and social crime prevention.

2.4.1. Law enforcement. Focus areas include:

(a) Improved criminal investigations

This can be achieved by implementing the following strategies:

- Sound detective management system,

- Crime intelligence,

- Specialized investigative units, and sharing the (workload) burden.

(b) Visible policing

This addresses specific crimes and fear of crime by implementing the following strategies:

- Preventive patrol,

- Directed patrol,

- $\quad$ Sector policing, and

- High density patrolling [8].

(c) Provision of adequate services to victims

Victimization constitutes a violation of human rights. Empowerment of criminals and victims of criminals and crime is an important element of police service delivery.

Improved victim support and empowerment can assist investigations and can be served as a means of altering public perceptions of police effectiveness thus enhancing public confidence in the police [6].

2.4.2. Situational crime prevention. Crime prevention through environmental design is implied here (Nel 200:7, [6]). This would involve measures such as CC TV systems, improving street lighting, clearing bushes and demolishing slums (informal settlements), etc.

These strategies diminish opportunities for crime by modifying the situations in which crimes are committed.

2.4.3. Social crime prevention. Social crime prevention refers to interventions which involve communities taking responsibilities for crime prevention and participating in community corrections operations and offender discharged reintegration in their own neighbourhoods.

Such interventions involve localized programmes which mobilize a range of interest groups $[6,8,5]$.

\subsection{Community corrections}

Community corrections is more accurately called community- based correctional services [5]. The concepts "Community corrections" describes 
sentences and models that provide alternatives to imprisonment $[11,3,1]$.

These community based programmes are intended to continue an offender's punishment, but in the contest of the community rather than in a correctional centre. Another term that is often used synonymously with community corrections is intermediate punishments.

Community corrections sentences and models are designed to consider both the safety of the local residents as well as the treatment needs of offenders.

Community corrections sentences recognize that some crimes do not require intervention which calls for imprisonment.

Sanctions developed within the community are alternatives to sentences that remove the offender from his or her family job and neighborhood. The underlying theme of community corrections is that justice is an active process. The offender must participate in this process.

Supporters of community corrections recognize that many offenders can still be valuable and contributing members of society despite having a criminal record (conviction).

The way corrections programmes are developed and operated cannot be understood outside the contest of a variety of socio-political in influences. Trends, in governments, economics, history and social movements all affect the policies that are formulated and implemented.

Legislatures, various structures of leadership, civilians, politicians, researchers and criminal justice practitioners may all have different views on what is necessary to make community corrections affective.

Yet for any programme to be successful they all must work together.

To assess the quality efficiency and effectiveness of present community corrections systems, we must first decide what it is we believe such a system should accomplish.

Our ideas and expectations about the goals of punishment are the cornerstone of our investigation into the value of our current system by critically analysing the operation and results of contemporary community corrections; we can visualize ways to improve the system.

Re-integration: The term refers to the process of re-inclusion of the discharged released offenders into the community.

The emphasis is mainly on the following aspects:

- The offender and the change in his or her inclinations and behaviour, and

- The community and how effectively rehabilitation is supported by the community in the re-integration process. Any form of correctional treatment must be linked to the offender's integration. Offenders must be prepared for new roles and accepted participation in community life is central to reintegration.

The following are important characteristics of reintegration:

- Close liaison between the correctional centre or community corrections office and the community is encouraged,

- Social reform in correctional centres through bridging the gap between in institutional and community life is emphasized,

- The offender is involved in the decision making process,

- Behavioural changes of the offender are noted, Correctional officials are involved in the rehabilitation process, and

- $\quad$ The community should be involved and should participate in offender's re-integration.

2.5.1 The use of community resources in community corrections operations and offender reintegration. At the heart- of community corrections movement are some assumptions about the nature of crime and the benefit of using community resources to address the problems of crime. These assumptions include the following:

- A correctional centre is a highly artificial society. Conformity in a correctional centre is not always a good indicator of the offender's ability to conform in the free community ,

- Because the community has resources that are not available in the correctional centre, the likelihood-of rehabilitation and re-integration is enhanced,

- The community can provide support networks to the offender that does not exist in a correctional centre. With the help members of their families and community at large, the offender has a greater chance of loading a law- abiding life,

- The offender can contribute to the financial upkeep of his or her family- if gainfully employed,

- The state spends less money on offenders in the community corrections programmes then it does in incarcerating them, and the Department of Correctional Services can accurately identify which offenders are dangerous and need secure incarceration and which ones are "safe" to release into the community.

\subsection{Current position}

Though South Africa has laws and legislation in place to try and ensure community involvement in reintegration of ex-offenders into the community, there still remain problems on this issue. The government's framework for community education, participation in community corrections operations and offender reintegration is contingent upon 
understanding the so-called "trias politica principle" that is, the governmental or state authority. Governmental authority in a state is divided into three commonly accepted components:

i. on the legislative authority;

ii. the judicial authority; and the

iii. the executive authority.

Legislative authority is a law-making body. It is, therefore, critical to note various legislation and policies that have a bearing the collective concept: 'Crime Prevention' (including Community Corrections and offender re-integration). An account of legislation presented in this paper is not exhaustive, but portrays arbitrarily selected statutory texts. Laws passed by parliament are known as 'Acts' whilst laws passed by local government are called 'by laws' [6]. Courts perform the adjudication (judicial) function. Two types of the cases are adjudicated, namely:

i. civil cases; and

ii. criminal cases.

In a civil case, a party (or parties) (which may be either an individual or a juristic person) approaches the court for assistance or relief, or for the making of a specific order. More simply stated, what this means is that the court will order someone.

In a criminal case, in contrast, it must be decided:

i. whether a crime has been committed;

ii. if so, who committed the crime; and

iii. what an appropriate punishment will be for the offender.

It should be noted that the police and Correctional officials perform the executive functions. Participation in community corrections operations and offender reintegration are important executive functions.

\subsection{National crime prevention strategy (1996)}

This document was produced by an interdepartmental strategy team consisting of the Departments of Correctional Services, Justice, Safety and Security, Defence and Social Development. The key to implement crime, prevention and to participate in community corrections operation and offender reintegration lies at the provincial and (local) traditional community levels. Funds are required to provide for ensuring effective community participation. This includes building the capacity to manage community corrections operations and offender re-integration projects in the short, medium and long term. The NCPS provides a National vision and planning at National level to ensure effective implementation at all spheres of government and effective learning (community education) and change. Four pillars constitute a framework for crime prevention [14].
2.7.1. Public (community) Values and Education. The prevailing moral climate within communities, attitudes towards crime and the willingness of citizens and communities to take responsibility for crime in reducing tolerance towards crime and hence levels (through participation in community corrections operations and offender re-integration projects). Community values and education cover strategies which are aimed at intervening the way in which the community engages with and responds to crime and conflict. Community education is a sharp instrument for influencing moral behavior. Given fiscal constraints, it is vital to improve community education and harness greater community participation.

\subsubsection{Community education aims to:}

- Provide citizens with a working understanding of the criminal justice system,

- to enable them to participate fully in the operations of the system.

- provide key information which underpins the development of strong community values and social pressure against criminality or 'grey' activities which support and sustain criminality (such as buying of stolen goods, drugs, etc.);

- promote non-violent means of conflict resolution, and hence reducing victimisation, domestic violence and other crimes of violence;

- $\quad$ promote awareness of gender issues; and

- promote awareness of the steps that the community can take to reduce the risk of victimisation and hence enhance the level of civic action directed at crime prevention (a holistic approach).

2.7.3. The Criminal Justice Process. An effective legitimate criminal justice system is a vital foundation for crime prevention and protection of human rights. This pillar focuses efforts on seven (7) key programmes designed to revamp and energise the criminal justice system as a whole:

i. re-engineering criminal justice process;

ii. criminal justice information and education;

iii. crime information and intelligence gathering;

iv. prosecutorial policy;

v. appropriate community sentencing, diversion programmes for minor offenders;

vi. $\quad$ secure care for juveniles;

vii. synergizing and rationalization of legislation and policies; and

viii. victim empowerment and support.

\subsubsection{Reducing crime through environmental}

design. The high incidence of many forms of crime is partly due to an environment which provides 
ample opportunities for crime and where risks of detection and prosecution are low. This pillar will extend the security-based design of residential buildings and other business centres. Ultimately the objective of this pillar is to ensure that safety and crime prevention considerations are applied in the development of all new structures and systems, and in the re-design and upgrading of old. Crime prevention through environmental design can be achieved by implementing the following programmes:

i. environmental design and maintenance;

ii. identification system;

iii. motor vehicle regulation; and

iv. dealing with corruption and crime.

2.7.5. National crime prevention. Large influence of international and regional criminal

syndicates is addressed through this pillar. Specific programmes focus on:

i. trans-national organised crime; and

ii. border control and ports of entry (National Key Points).

The community have a role to play in crime prevention and breaking the cycle of recidivism and may even refine this NCPS - this will in turn culminate in participation in community corrections operations and offender re-integration. The community may initiate a multi-agency co-ordinating committee to establish how best to implement and participate in community corrections operations and offender re-integration.

\subsection{Constitution of the republic of South Africa (1996)}

The constitution provides for traditional leadership as an institution at local, and national and provincial legislation provides for the establishment of Houses of Traditional Leaders (section ZIZ (1) \& 2(a); Traditional Leadership and Governance Framework Act, 2003). The KwaZulu-Natal government passed the Traditional Leadership and Governance Act no. 5 of 2005 in order to fulfil certain obligations. Aspects (rights) necessitating community participation in crime prevention are enshrined in chapter 2 (Bill of rights) of the constitution. For example, the community is mandated to receive education and participate to prevent crime in respect of the following rights which include:

- Freedom to receive and impart information or ideas;

- Academic freedom and freedom of scientific research;

- Freedom of association;

- The right to have dignity, respect and protection;

- $\quad$ The right to life;
- $\quad$ The right to be free from all forms of violence;

- $\quad$ No one has to be deprived of her property;

- The right to education; etc. (section 10, 11, 12, $16,18,25$ \& 29).

In order to provide re- integration and support of ex offenders into community there is a need for address of conspicuous gaps. The lack of education and lack of support of ex offenders adversely affect the re-entry process and are considered obstacles. These gaps need to be filled through collaboration of the public and private sectors of the community.

In Mr. Ben Skosana's speech at the Nicro/DCS offender reintegration symposium in October 2003, he referred to the community integration as the need to recognise men and women returning from jail as members of the community. He further said 'a focus on community integration means heightening public awareness and building political will in favour of supporting, rather, than merely controlling offenders.' Successful reintegration of ex offenders will contribute to the reduction of recidivism.

\section{Methodology}

Permission was obtained from Inkosi Mkhwanazi's tribal council. It was proposed that education of community members be facilitated over the weekends.

A training manual was compiled and students from the Department of Criminal Justice were trained to facilitate in educating the community. Students were to educate the community under the supervision of Dr. V.I. Khoza and Ms. C.Z. Zondi, both from the Department of Criminal Justice.

During the project the Department worked closely with the Tribal Secretary Ms. Duyu Shandu (former student of Dept. of Criminal justice) who provided with the list of 15 induna's under inkosi Mkhwanazi and their areas of operation. In that way it was easy to communicate directly with them to arrange dates when they can be educated.

Most of the information was gathered from the tribal council through participant observation and discussion during the introduction of the project. A tentative programme was drawn but they suggested we contacted individual indunas for suitable dates, venues and times. The information was also obtained from community members who participated in the workshops.

The Department of Correctional Services was also invited to participate and contribute in educating the community but was not available.

Workshops were conducted on Sundays and each workshop started at $10 \mathrm{~h} 00$ and went until $12 \mathrm{~h} 00$. At the end of each session there was a slot for questions and answers. The workshop in the area under induna Sandile Mthethwa (Port Durnford), there seemed to have been problems and the workshop was not a success. At Esikhaleni senkosi, the area under induna 
Mwandla there were more than 50 community members who were present.

Information gathered outside of the workshop, included interviews with indunas Bhekinkosi Mpanza, Kakinkosi Khanyile, Sandile Mthethwa, Mboniseni Mwandla and Bhekinkosi Mpanza.

The reason for primarily using discussions, interviews and participant observation were to successfully cofacilitate workshops while gathering data at the same time. Through this approach information was gathered on how successful the project itself was as well as to collect information. Clearly the presence of the researcher positively affected the workshops and it would probably not have been the same had I allowed that the students facilitated all by themselves.

\section{Observations}

During the first meeting with the tribal council, it was very tense. The fact that the project had to do with offenders angered the council members. One induna talked about his past experience as crime victim and was vocal in opposing the project. One member of the council said the researchers are condoning acts of criminals in the same manner as the Government who treats criminals with respect, when they are in Correctional Centres.

During the second meeting when the proposal was explained to them and brief clarity on the objectives of the project were presented, though the council members still had a lot of questions the atmosphere was a relatively relaxed. They had questions that were not related to this project. Induna Mthethwa had to intervene and explain to them that this project was from the University and not the Department of Correctional Services.

Notices were sent to community members through indunas for the dates and venues of the workshops.

\section{The workshop}

In terms of ethical issues, before we the workshop started the induna explained the reason for our presence to the participants and the objectives of the project. This assisted in building trust from the participants.

The workshop started by explaining the purpose of the project followed by educating the community to support offenders and build relationships between ex offenders and the community which would assist in solving the problem of recidivism. Towards the end, time was set aside for questions and answers.

At the beginning of the workshops participants were passive and silent. They were all attentively listening. As the workshop proceeded there was distinct change of attitude. They had confidence in themselves and they were assertive in voicing their opinions.

There were many issues and difficulties that arose through the workshop. One of the biggest problems was that community members lack knowledge of the work of Department of Correctional Services. This created a problem in educating them about their role in reintegrating ex-offenders. Community members regarded a person who had been incarcerated as a prisoner. Officials from DCS were blamed simply because they were seen visiting them. The other reason was that workshops were conducted on Sundays. The component for Community Services in the Department of Correctional Services does not operate during weekend. It was, therefore, difficult to get members from this component.

Additionally, in terms of participation, community members did not see the importance of attending these workshops. One induna did say that people were reluctant to attend meetings where nothing would be given to them in the form of tshirts or food parcels. They always wanted to bring something home after the meetings.

The most noticeable thing was that parents whose children are known to be delinquents were not vocal. The reason was that they were blamed for the behaviour of their children. One participant said that these children who are delinquents are sent by their parents to break into other people's houses because they benefit from stolen goods.

\section{Educating the community about the nature of community corrections and offender reintegration}

The primary purpose of community corrections programs is to assist offenders in becoming reintegrated into their communities. The community has to perform productive work to support them. A secondary purpose of community corrections is to alleviate overcrowding in correctional centres by accepting those offenders who are not dangerous and pose the least risk to society.

Perhaps community corrections are such a fuzzy concept, suffering such accidental inclusions and exclusions, that it simply does not denote anything systematically or informally. It may be quite helpful to become more specific in listing characteristics of community corrections [5]:

a. Community corrections are innovative. It is essential that the community should be creative in devising 'new' ways of improving involvement and participation in community corrections operations and offender reintegration.

b. Service provision would reduce crime. It is therefore important that resources should be made available. 
c. Community corrections should change the relationship between the offender and the community.

d. Community corrections require local government effort and the local constituency. This illustrates the significance of community participation in the realization of successful offender re-integration.

e. Community corrections avoid the use of correctional centres.

f. Community corrections have significant sanction value and are compatible with the demand for retribution and may be quite useful if we are concerned with restorative justice.

g. Community corrections provide us with greater diversity in correctional options than is possible in 'non - community' settings, and that part of this diversity is brought about by the increased competition observed in community corrections.

\subsection{The goals of community corrections}

The goals of community corrections include:

6.1.1. Facilitating offender re-integration. It is considered advantageous for the community and community corrections officials to supervise as many offenders as possible. Continued community involvement and participation means continuous and hopefully positive contact with offender's family and close friends. Also, there is a broader range of social and psychological services available compared with their opportunities for personal growth and development while in correctional centre. Convicted offenders who remain free in their communities could help with community-based correction programming operating costs, work to support themselves and their families, and take advantage of vocational technical and educational programmes available through local tertiary institutions e.g. universities. Some offenders require closer monitoring than others. Therefore, it is imperative that community-based correctional programs devise effective screening mechanisms for their clients in order to diagnose their needs. Offender re-integration is, therefore, an important objective of communitybased correctional programs in South Africa.

6.1.2. Fostering offender rehabilitation. A major goal of any community-based correctional program is rehabilitation. Rehabilitation occurs when community corrections clients (offenders) participate in vocational, educational and/or counseling programs that are intended to improve their coping skills. The beneficial value of these programmes should not be overlooked. It should pay dividends to observe recidivism rates among community-based correctional clients compared with offenders who have been incarcerated.
6.1.3. Providing an alternative range of offender punishments. The range of punishments is vast within community corrections. Programs are tailored to fit clients from diverse age groups, include those with diverse needs. It should be ideal to work with special problems offenders such as addictions to drugs or alcohol, learning disabilities or vocational educational deficiencies. Community centers should be created under community corrections acts to assist clients in filling out job applications or overcoming educational problems (illiteracy), and /or use should be made of existing facilities. The private sector should become increasingly involved and should participate in the treatment of community based correctional clients [4].

6.1.4. Heightening offender accountability. It may be argued that unsupervised community corrections are unsuccessful in rehabilitation and reintegration of offenders. One aim of community corrections, therefore, is to provide substantial supervision and services to offenders. For example, substance abusers comprise a class of clients requiring special assistance and intervention. Often these offenders have committed crimes in the past to acquire drugs or alcohol they need to satisfy their addictions. With appropriate intervention and accountability mechanisms established, many of these offenders can overcome their addictions and accept responsibility for their actions. Over time, they learn to cope and overcome their substance dependencies to the extent that they can perform full-time jobs and support their dependants. Heightening offender accountability is a key goal of community-based correctional programmes.

\section{The functions of community corrections}

Community corrections perform the following functions:

\subsection{Client (offender) monitoring and supervision to ensure community corrections compliance}

When offenders are sentenced to a community corrections program, it is expected that they will comply with all programme conditions. Victim compensation, restitution, community service, house arrest, employment refrains from using or abusing alcohol or abusing drugs, refrains from crime, etcare often programme components or conditions relating to community corrections [9]. The nature of their supervision is more or less intense in secure programme compliance. Community safety is enhanced to the extent that, programme requirements are enforced by community corrections officials. 
Measures must be established to ensure that offenders comply with court orders and participate in designed programmes.

\section{Limitations of the study}

While this study was very successful and a lot of information was gathered, there were also several limitations. Firstly there was time constraint in that the workshop was only a three hour workshop. Because of this the workshop was only short term, which means it did not have the impact a more sustained workshop could have had. Secondly, because the project was short, it could not be observed what the long-term effects of the workshop were, if any.

The study was also limited by the conditions of the workshop. The workshop being held in the presence of induna limited discussions due to the fear of induna hearing them talking negatively about other aspects.

A final limitation was the unavailability of members of DCS.

\section{Conclusion}

Having one induna stating that 'we cannot allow that these people who had wronged the community be welcomed and supported by the same community they wronged,' as demonstrated in this article is evident of lack of education of community members.

Community members who participated in workshops admitted that they saw challenges that they are faced with in reintegration and support of ex-offenders.

In conclusion these projects need to be an ongoing process and participation of DCS members be encouraged.

\section{References}

[1] Champion, D.J. (2005): Probation, Parole and Community Corrections. Fifth edition. Upper Saddle River, New Jersey: Prentice-Hall.

[2] Camp, C.G. \& Camp G. M. (2003) The Corrections Yearbook 2002. Middletown: Criminal Justice Institute Inc.
[3] Fuller, J.R. (2006) Criminal Justice: Mainstream crosscurrents. Upper New Jersey: Prentice- Hall.

[4] Haulard, E.R. (2001) "Adult Education: A must for our incarcerated population”. The journal of Correctional Education, 52.

[5] Khoza, V.I. (2003) Targeting the offender population: a community criminal justice approach to crime prevention.Unpublished manuscript. Kwa-Dlangezwa: University of Zululand.

[6] Khoza, V.I., Gumbi, T.A.P. \& Zulu, N.M.C. (2006) A Social Crime Prevention Training Manual for Traditional Leaders in KwaZulu-Natal. Kwa-Dlangezwa: University of Zululand.

[7] Skosana, B. M. 2003 Nicro /DCS Offender Reintegration Symposium, Mykonos, Langebaan.

[8] South Africa White Paper on Safety and Security (1998-2004).

[9] South Africa Correctional Services act (Act no. 111 of 1998).

[10] Peak, K.J.\& Glensor, (2004) Policing and problemSolving: Strategies and Practices. Forth edition. Upper Saddle River, New Jersey: Prentice - Hall.

[11] Reichel, P.L. (2001) Corrections: Philosophies, Practices and Procedures. Boston: Allyn\& Bacon.

[12] Peak, K.J. (2001) Justice Administration: Police, Courts and Corrections Management. Third edition. Upper Saddle River, New Jersey: Prentice-hall.

[13] Reid, S.T. 1981The Correctional System. New York: Hold, Reinehart and Winston.

[14] South Africa, National Crime Prevention Strategy (1996).

[15] South Africa, Traditional Leadership and Governance Framework Act (Act no. 41 of 2003).

[16] Utting, D. \& Vennard, J. (2000). What works with young offenders in the community. Essex, U.K.: Barnado's.

[17] Van der Walt, P.J., Cronje, G. And Smit, B.F. 1982. An Introduction to Criminological Research. Pretoria: Haum.

[18] Paper on Corrections in South Africa (2004). 